\title{
Study of Linke Turbidity Factor over Bode, Bhaktapur
}

\section{P. M. Shrestha, N. P. Chapagain, I. B. Karki, K. N. Poudyal}

\section{Journal of Nepal Physical Society}

Volume 6, Issue 2, December 2020

ISSN: 2392-473X (Print), 2738-9537 (Online)

\section{Editors:}

Dr. Binod Adhikari

Dr. Bhawani Joshi

Dr. Manoj Kumar Yadav

Dr. Krishna Rai

Dr. Rajendra Prasad Adhikari

Mr. Kiran Pudasainee

JNPS, 6 (2), 66-73 (2020)

DOI: http://doi.org/10.3126/jnphyssoc.v6i2.34859

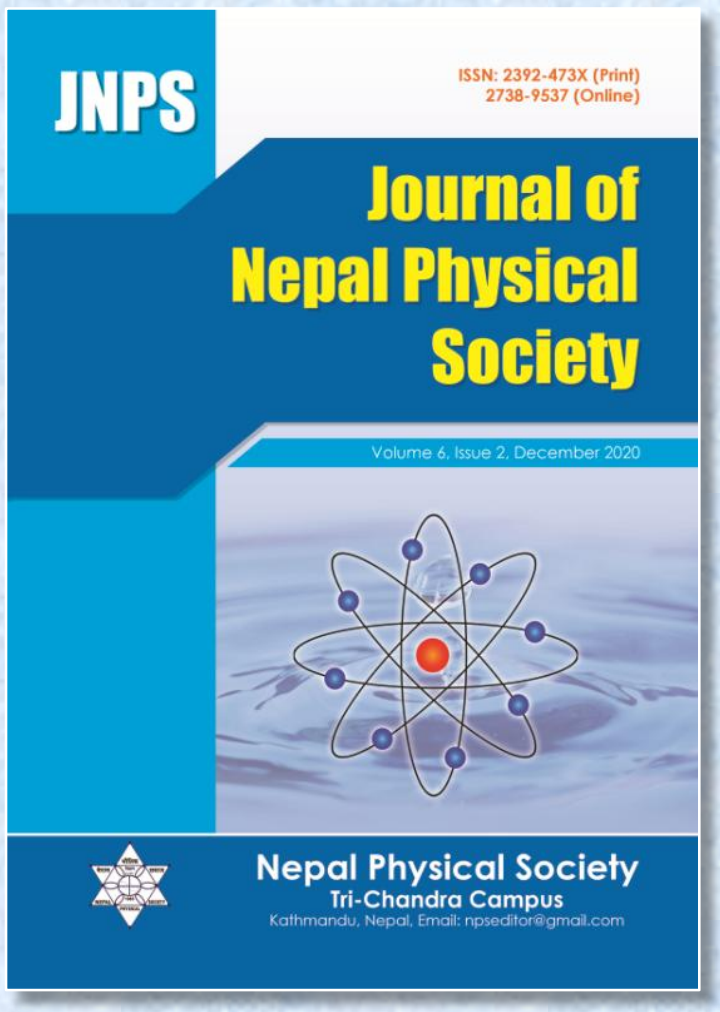

Published by:

Nepal Physical Society

P.O. Box: 2934

Tri-Chandra Campus

Kathmandu, Nepal

Email: npseditor@gmail.com 


\title{
Study of Linke Turbidity Factor over Bode, Bhaktapur
}

\author{
P. M. Shrestha' ${ }^{* 1}$, N. P. Chapagain ${ }^{2}$, I. B. Karki ${ }^{3}$, and K. N. Poudyal ${ }^{4}$ \\ ${ }^{1}$ Department of Physics, Patan Multiple Campus, IoST, T. U., Nepal \\ ${ }^{2}$ Department of Physics, Amrit Campus, IoST, T.U., Nepal \\ ${ }^{3}$ Nepal Open University, Nepal \\ ${ }^{4}$ Department of Physics, Pulchowk Engineering Campus, IoE, T. U., Nepal \\ *Corresponding Email: prakash.shrestha@ pmc.tu.edu.np
}

Received: 10 October, 2020; Revised: 18 November, 2020; Accepted: 26 December, 2020

\begin{abstract}
The daily aerosol optical depth (AOD) data are derived from AERONET over Bode, Bhaktapur $\left(27.68^{\circ} \mathrm{N}, 85.39^{\circ} \mathrm{E}, 1297 \mathrm{~m}\right.$ above sea level) for a period of one year 2013. Annual mean of Atmospheric turbidity factors are calculated. The effect of different physical as well as meteorological parameters on the Linke turbidity factor was analyzed. The yearly mean of solar insolation, Angstrom exponential $(\alpha)$,Angstrom coefficient of turbidity $(\beta)$ and Linke turbidity $\left(\mathrm{L}_{\mathrm{T}}\right)$ were found $4.70 \pm 1.10 \mathrm{kWh} / \mathrm{m}^{2} / \mathrm{day}, 1.13 \pm 0.21,0.18 \pm 0.14$ and $5.70 \pm 2.46$ respectively. Annual average of visibility is $2.98 \pm 2.13 \mathrm{~km}$. Result of this research work is beneficial for the further identification, impact and analysis of atmospheric turbidity at different places.
\end{abstract}

Keywords: Aerosol, Angstrom exponential, Angstrom turbidity, Linke turbidity, solar insolation.

\section{INTRODUCTION}

Sun is the closest star from the Earth. Solar energy has been identified as the largest renewable resources of energy for earth. Solar energy passing through the atmosphere is scattered and absorbed by molecules and particles. Solar energy interacts with large particle of atmosphere such as water droplets, dust and aerosol. The opacity of atmosphere for solar energy gives atmospheric turbidity. Study of atmospheric turbidity and its dependence on different meteorological parameters are used agriculture, hydrology, and Climate change.

Nepal is a land locked south east mountainous Asian country with a large area of beautiful landscape. Within this small and beautiful setting it possesses diversity in biosphere and variation of climate. Nepal lies in sun belt (latitude $15^{\circ}$ to $35^{\circ}$ ). Annual solar isolation is 3.6 to $6.2 \mathrm{kWh} / \mathrm{m}^{2} /$ day and sunshine duration is 300 days in Nepal [1]. In FY 2016/017, 538.6 TJ energy is consumed in which traditional fuel is $73 \%$, commercial fuel is $25 \%$ and renewable energy is $2 \%$ [2]. 4,37,614 vehicle register in Nepal in BS 2074/075 [3]. Large foreign currency is used to export petroleum product. Due to petroleum fuel based vehicle, air pollution increases. Study of air pollution is needed.

Kathmandu Valley (combination of Kathmandu, Lalitpur and Bhaktapur districts) covers area 893 $\mathrm{km}^{2}$. Kathmandu valley is bowl shaped. Kathmandu valley is surrounded by four mountain ranges: Shivapuri at north, Phulchowki at south, Nagarjun Hill at North West and Chandragiri at west. The maximum and minimum global solar radiations (GSR) are $25.3 \mathrm{MJ} / \mathrm{m}^{2} /$ day and $14.6 \mathrm{MJ} / \mathrm{m}^{2} /$ day in May and January respectively. The annual average solar energy measuring $5.19 \mathrm{kWh} / \mathrm{m}^{2} /$ day is found in Kathmandu from 2009 to 2010[4]. The average values attenuation coefficient in Kathmandu during the pre-monsoon period of 1999 is found to be $0.6027 \pm 0.022$ respectively [5]. The values of Angstrom coefficient of turbidity $(\beta)$ found to vary from $0.16 \pm 0.03$ to $0.35 \pm 0.15$ with high values in summer and low values in winter from December 2011 to March 2013[6]. The yearly mean of atmospheric transmittance due to Rayleigh 
scattering followed by ozone, water vapor, gas mixture and aerosols are found 0.889, 0.983, $0.881,0.987$ and 0.698 respectively for 2012 on Kathmandu Valley((Lat.:27.72 ${ }^{\circ} \mathrm{N}$, Long.: $85.32^{\circ} \mathrm{E}$ and alt.: $1337 \mathrm{~m}$ a.s.l.) [7].

Bode $\left(27.68^{\circ} \mathrm{N}, 85.39^{\circ} \mathrm{E}, 1297 \mathrm{~m}\right.$ above sea level $)$ is an ancient Newari city in the east corner of the Kathmandu Valley, lies in Bhaktapur district. It covers area 0.41 sq. $\mathrm{km}$, has population 6,364 with 1389 houses and population density 16,000 per sq. $\mathrm{km}$ [8].Map of Bode is shown in figure 1.Due to high population density, air pollution may high. So study of air pollution is required. The average value of Angstrom exponential $(\alpha)$ is $1.18 \pm 0.1712$ and Angstrom coefficient of turbidity $(\beta) 0.20 \pm 0.1315$ from December 2012 to July 2016 [9].

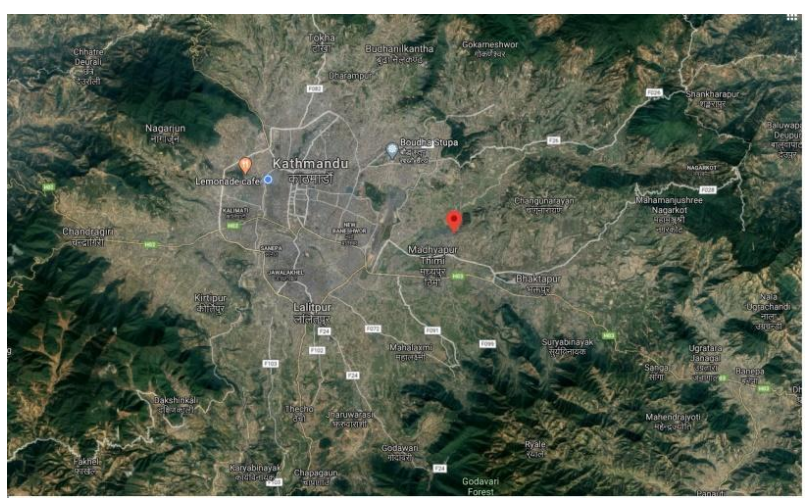

Fig. 1: Map of Bode [source: www.google.map.np]

\section{METHODOLOGY AND MATERIAL}

By Beer Lambert's law, direct normal solar spectral irradiance on outer layer of atmosphere $\left(I_{0} \lambda\right)$ is attenuated exponentially in atmosphere due to absorption, reflection, scattering. Then direct normal solar spectral irradiance on ground $\left(\mathrm{I}_{\lambda}\right)$ is[10]

$$
I_{\lambda}=I_{o \lambda} e^{-K_{\lambda} m}
$$

Here $m$ is optical air mass and $\mathrm{K}_{\lambda}$ is total extinction coefficient (total optical depth). Total extinction coefficient is sum extinction coefficient due to ozone $\left(\mathrm{K}_{\mathrm{o} \lambda}\right)$, mixed gas $\left(\mathrm{K}_{\mathrm{g} \lambda}\right)$, water vapor $\left(\mathrm{K}_{\mathrm{w} \lambda}\right)$, aerosols $\left(\mathrm{K}_{\mathrm{a} \lambda}\right)$ and Rayleigh scattering $\left(\mathrm{K}_{\mathrm{r} \lambda}\right)$. The aerosol extinction coefficient $\left(\mathrm{K}_{\mathrm{A} \lambda}=\mathrm{K}_{\mathrm{w} \lambda}+\mathrm{K}_{\mathrm{a} \lambda}\right)$ is also called as aerosol optical depth (AOD). According to Angstrom relation [11]

$$
\mathrm{K}_{\mathrm{A \lambda}}=\beta \lambda^{-\alpha}
$$

Angstrom turbidity coefficient $(\beta)$ measures the aerosol concentration and accounts for all scattering constituents other than Rayleigh. Angstrom exponential $(\alpha)$ is particle size distribution. $\alpha$ and $\beta$ are calculated by linear regression method. Spectral bands $675,500,440,380$ and $340 \mathrm{~nm}$ is used.

$\log \left(\mathrm{K}_{\mathrm{A} \lambda}\right)=\log (\beta)-\alpha \log (\lambda)$

According to Dogniaux (1974)[12], Linke turbidity factor is

$L_{T}=\left(\frac{85+\gamma}{39.5 e^{-w}+47.4}+0.1\right)(16+0.22 w) \beta$

Here $\gamma$ is solar height $\left(90-\theta_{z}\right)$ and $w$ is water content in $\mathrm{cm}$. Solar zenith angle $\left(\theta_{\mathrm{z}}\right)$ is function of solar declination $(\delta)$, latitude $(\phi)$ of the place, solar hour angle $(\omega)$ and day no. of year $\left(\mathrm{n}_{\mathrm{d}}\right)$ [13]

$\theta_{z}=\cos ^{-1}(\sin \delta \sin \phi+\cos \delta \cos \phi \cos \omega)$

$\delta=23.45 \sin \left(\frac{360}{365}\left(284+n_{d}\right)\right)$

Atmospheric transmittance of aerosol is $[14,15]$

$$
\begin{aligned}
\tau_{a}=(0.1244 \alpha & -0.0162) \\
& +(1.003 \\
& -0.125 \alpha) e^{-\beta m_{a}(1.089 \alpha+0.5123)}
\end{aligned}
$$

Where optical air mass is

$m_{a}=\frac{P}{101325} \frac{1}{\cos \theta_{z}+0.15\left(93.885-\theta_{z}\right)^{-1.253}}$

$\mathrm{P}=$ atmospheric pressure at the place

The spectral aerosol optical depth data of Bode from 2013 measured by CIMEL -318 sun photometer are available in the AERONET homepage of NASA. It is multichannel radiometer which measures direct solar irradiance. Solar insolation data are collected from [https://power.larc.nasa.gov/data-access-viewer/].

Meteorological data are collected from [https://www.worldweatheronline.com/].

Open source software Python 3.7 software is used to analysis data and plot graph. Mean standard deviation, correlation coefficient are used as Statistical tool. Standard error is used as error bar in graph. Least square method is used to find trend line.

\section{RESULTS AND DISCUSSION}

Figure 2(a) indicates daily variation of spectral AOD. The maximum value of AOD for $675 \mathrm{~nm}$, $500 \mathrm{~nm}, 440 \mathrm{~nm}, 380 \mathrm{~nm}$ and $340 \mathrm{~nm}$ are in $68^{\text {th }}$, 
$68^{\text {th }}, 68^{\text {th }}, 91^{\text {th }}$ and $67^{\text {th }}$ day of year (DOY) respectively due to high temperature. The minimum value of AOD for $675 \mathrm{~nm}, 500 \mathrm{~nm}, 440 \mathrm{~nm}, 380$ $\mathrm{nm}$ and $340 \mathrm{~nm}$ are in $143^{\text {th }}$ day of year (DOY) due to low temperature. Figure 2(b) shows daily variation of Angstrom exponential $(\alpha)$. The maximum value of $\alpha$ is in $143^{\text {th }}$ day of the year due to present of large no. of smaller particle and minimum value in $82^{\text {th }}$ day of the year due to present of large no. of big particle. Figure 2(c) shows daily variation of Angstrom turbidity coefficient $(\beta)$. The maximum value of $\beta$ are in $68^{\text {th }}$ day of the year due to present of large no of aerosols and minimum value is in $143^{\text {th }}$ day of the year due to present of small no. of aerosols. Figure 2(d) shows daily variation of Linke turbidity $\left(\mathrm{L}_{T}\right)$. The maximum value of $\mathrm{L}_{\mathrm{T}}$ are in $68^{\text {th }}$ day of year due to air pollution and minimum value is in $217^{\text {th }}$ day of the year. Statistics of those parameters are shown in Table 1.

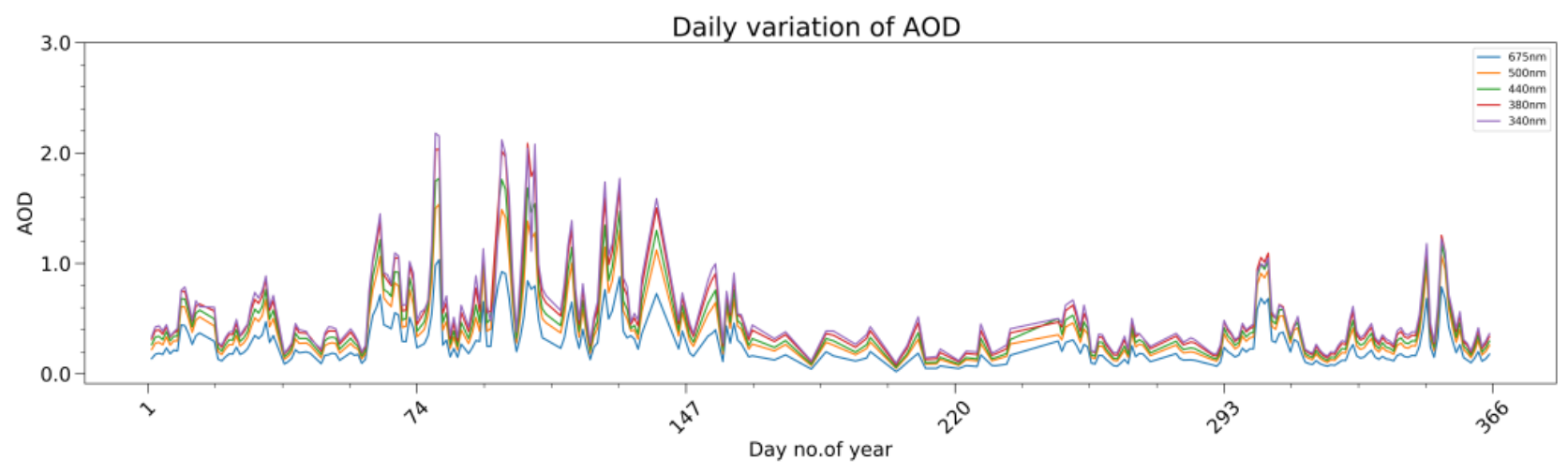

a)AOD

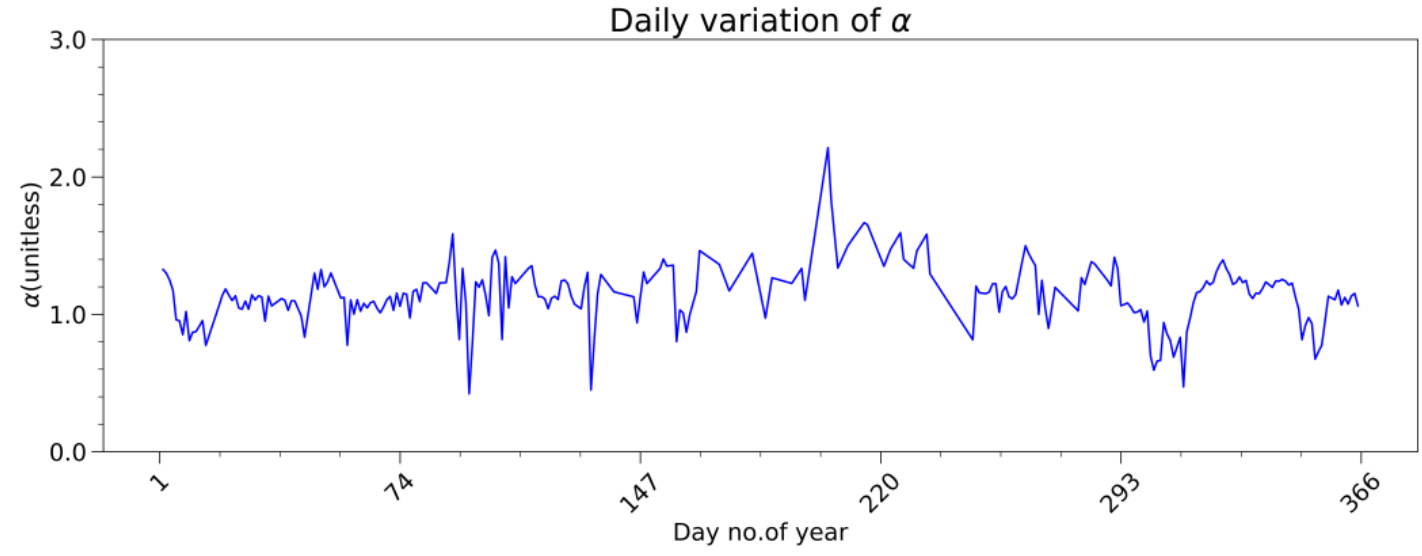

b) Angstrom exponential

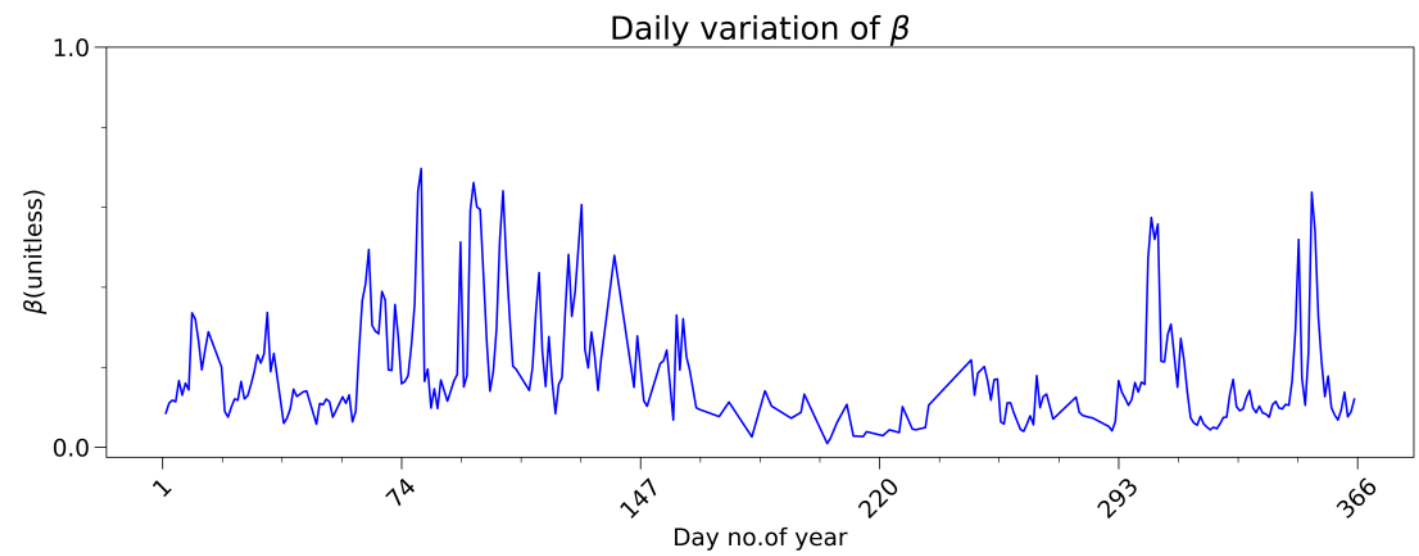

c) Angstrom turbidity coefficient 


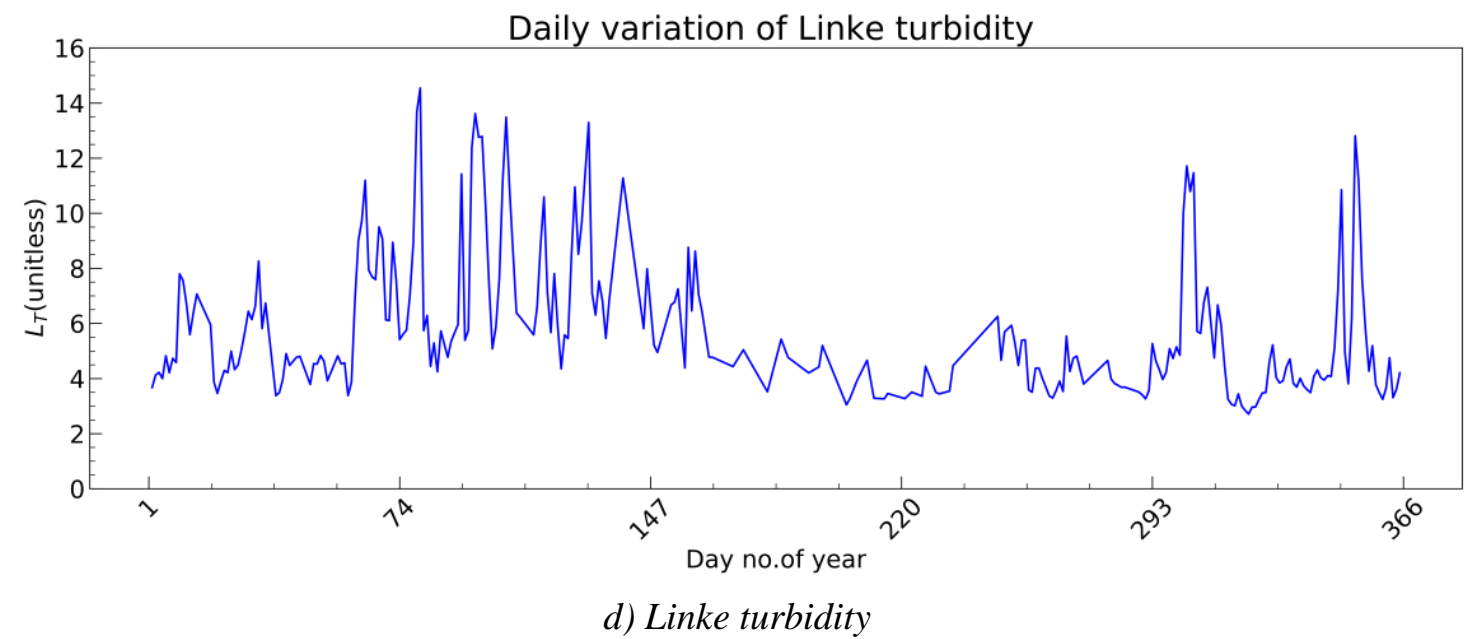

Fig. 2: Daily variation of parameters (AOD, Angstrom exponential, Angstrom turbidity coefficient, Linke turbidity)

Table1: Statistics of parameters

\begin{tabular}{|l|l|l|l|l|}
\hline \multicolumn{1}{|c|}{ Parameters } & \multicolumn{1}{c|}{ Max. } & \multicolumn{1}{c|}{ Min. } & \multicolumn{1}{c|}{ Mean } & \multicolumn{1}{c|}{ sd } \\
\hline AOD for 675nm & 1.0333 & 0.0208 & 0.2724 & 0.1938 \\
\hline AOD for 500nm & 1.5361 & 0.0507 & 0.4054 & 0.290 \\
\hline AOD for 440nm & 1.7706 & 0.0584 & 0.4680 & 0.3364 \\
\hline AOD for 380nm & 2.0871 & 0.0797 & 0.5395 & 0.3842 \\
\hline AOD for 340nm & 2.1790 & 0.0971 & 0.5673 & 0.3905 \\
\hline$\alpha$ & 2.21 & 0.42 & 1.13 & 0.21 \\
\hline$\beta$ & 0.69 & 0.01 & 0.18 & 0.14 \\
\hline$T_{L}$ & 14.54 & 2.71 & 5.70 & 2.46 \\
\hline
\end{tabular}

Figure 3(a) indicates monthly variation of solar insolation .The maximum value of solar insolation is $6.15 \pm 6.15$ in May due to large day length and small solar declination and minimum value of 3.73 \pm 1.55 in October due to small day length and large solar declination. Figure 3(b) shows monthly variation of Angstrom exponential $(\alpha)$. The maximum value of $\alpha$ is $1.48 \pm 0.12$ in July due to rainy season and minimum of $1.05 \pm 0.14$ in January. Figure 3(c) shows monthly variation of Angstrom turbidity coefficient $(\beta)$.The maximum value of $\beta$ is $0.33 \pm 0.17$ in April due to high temperature and minimum value of $0.05 \pm 0.02$ in July due to rain. Figure 3(d) shows monthly variation of Linke turbidity $\left(\mathrm{L}_{\mathrm{T}}\right)$.The maximum value of $L_{T}$ is $8.55 \pm 2.82$ in April due to high temperature and minimum value of $3.62 \pm 0.42$ in July due to rain. Figure 3(e) shows monthly variation of transmittance of aerosol $\left(\tau_{\mathrm{a}}\right)$.The maximum value of $\tau_{\mathrm{a}}$ is $0.8846 \pm 0.045$ in July and minimum value of $0.6656 \pm 0.1191$ in April.

According to Koschmier (1924)[16] ,visibility in $\mathrm{km}$ is

$$
V_{m}=\frac{0.693}{b_{\text {ext }}}
$$

Here $b_{e x t}$ is AOD for 550nm wavelength. Figure 3(f) shows monthly variation of visibility. Maximum value of visibility is $6.54 \pm 2.28 \mathrm{~km}$ in August and minimum value of $1.33 \pm 0.62 \mathrm{~km}$ in April. 


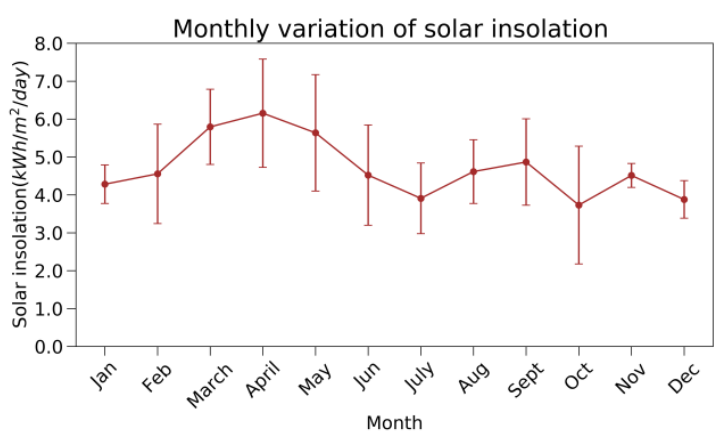

a) Solar insolation

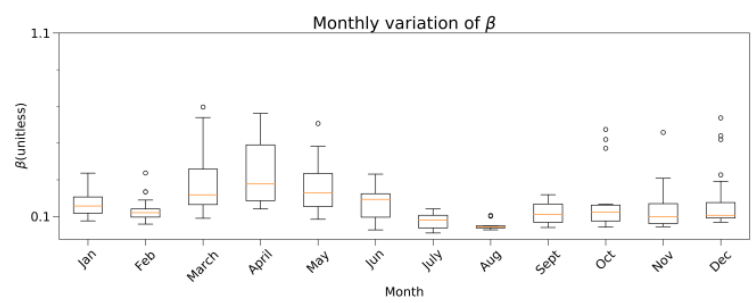

c) Angstrom turbidity coefficient

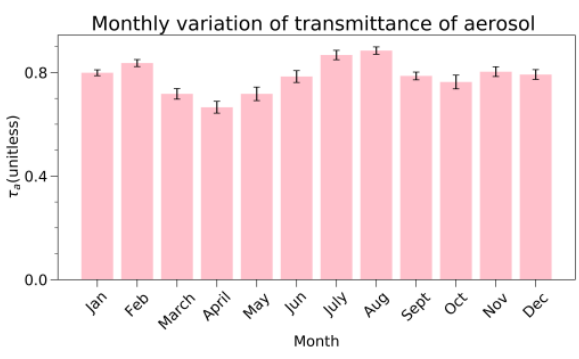

e) Transmittance of aerosol

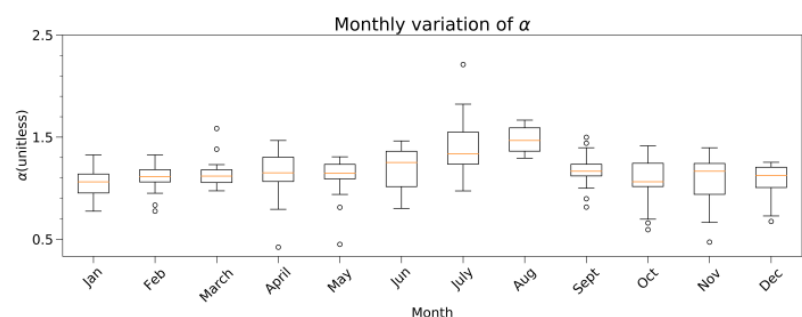

b) Angstrom exponential

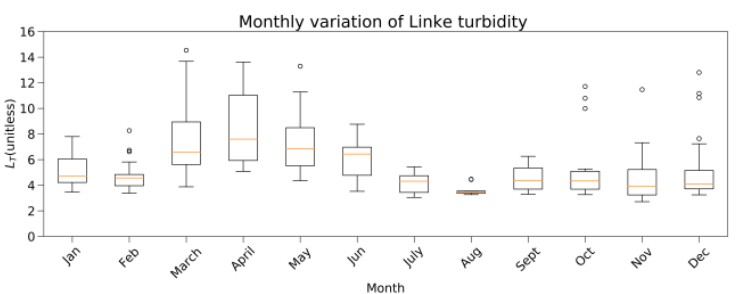

d) Linke turbidity

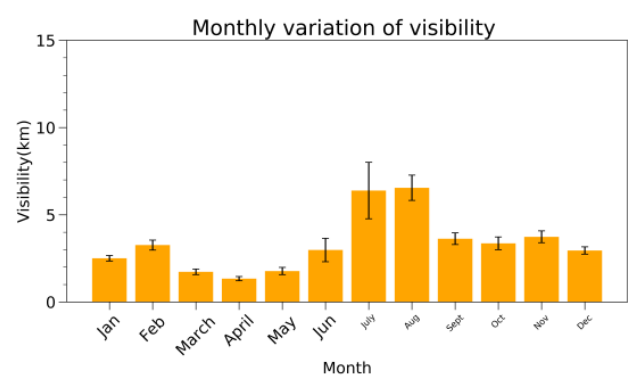

d) Visibility

Fig. 3: Monthly variation of parameters (Solar insolation, b) Angstrom exponential, Angstrom turbidity coefficient, Linke turbidity, Transmittance of aerosol, Visibility)

Figure 4(a) shows seasonal variation of Angstrom exponential $(\alpha)$. The maximum value $\alpha$ is $1.34 \pm$ 0.24 in summer and minimum value of $1.07 \pm 0.14$ in winter. Figure 4(b) shows variation of Angstrom turbidity coefficient $(\beta)$.The maximum value of $\beta$

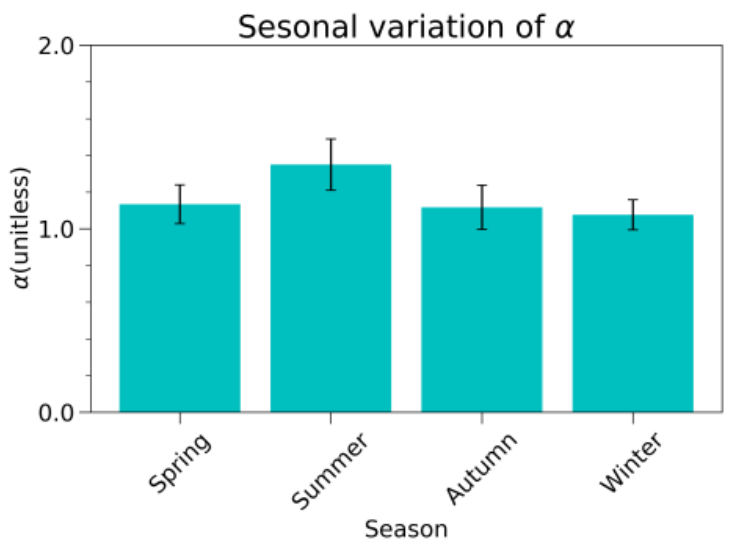

a) Angstrom exponential is $0.29 \pm 0.15$ in spring and minimum value of 0.10 \pm 0.06 in summer. Figure 4(c) shows seasonal variation of Linke turbidity $\mathrm{L}_{\mathrm{T}}$ ). The maximum value of $L_{T}$ is $7.79 \pm 2.6$ in summer and minimum value of $4.69 \pm 1.79$ in autumn.

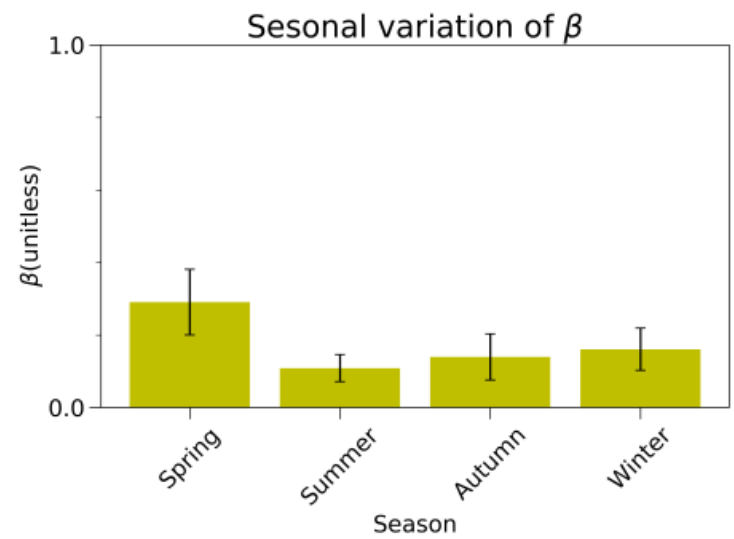

b) Angstrom turbidity coefficient 


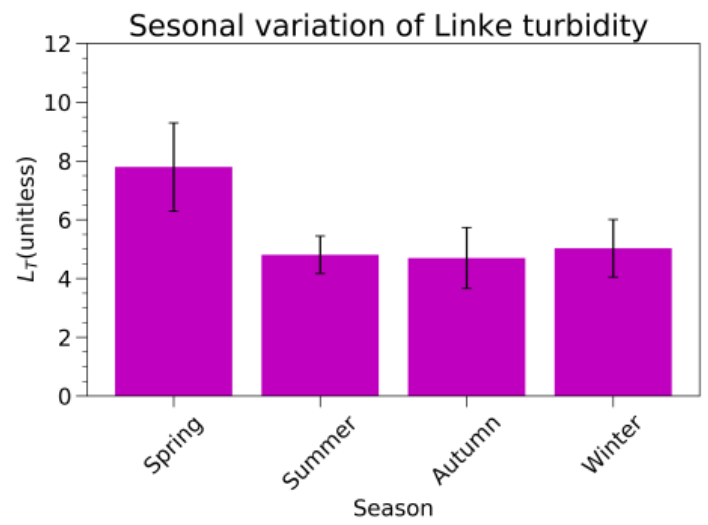

c) Linke turbidity

Fig. 4: Seasonal variation of parameters (Angstrom exponential Angstrom turbidity coefficient, Linke turbidity)

Figure 5(a) shows variation of Linke turbidity with maximum temperature. Correlation coefficient is 0.23 . The annual mean of maximum temperature is $21.2 \pm 4.1^{\circ}$ C.Figure 5 (b) shows variation of Linke turbidity with minimum temperature. Correlation coefficient is 0.07 . The annual mean of minimum temperature is $10.5 \pm 5.8^{\circ} \mathrm{C}$. Linke turbidity is less correlated with temperature. Figure 5(c) shows variation of Linke turbidity with relative humidity. Correlation coefficient is -0.57 . The annual mean of relative humidity is $59.9 \pm 18.5 \%$. Figure $5(\mathrm{~d})$ shows variation of Linke turbidity with cloud percentage. Correlation coefficient is -0.36 .

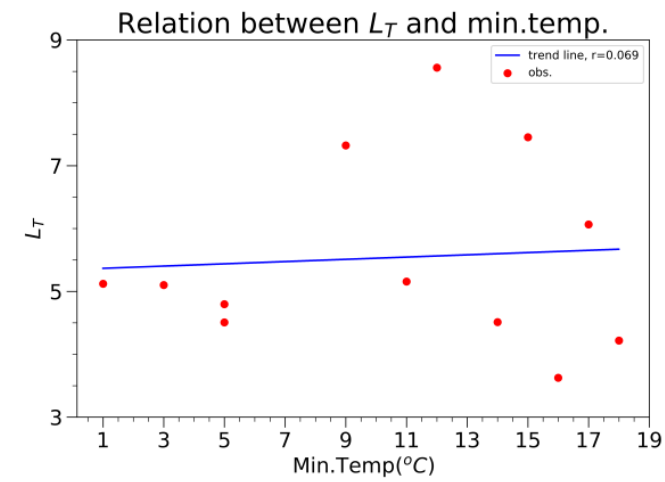

b)Minimum temperature

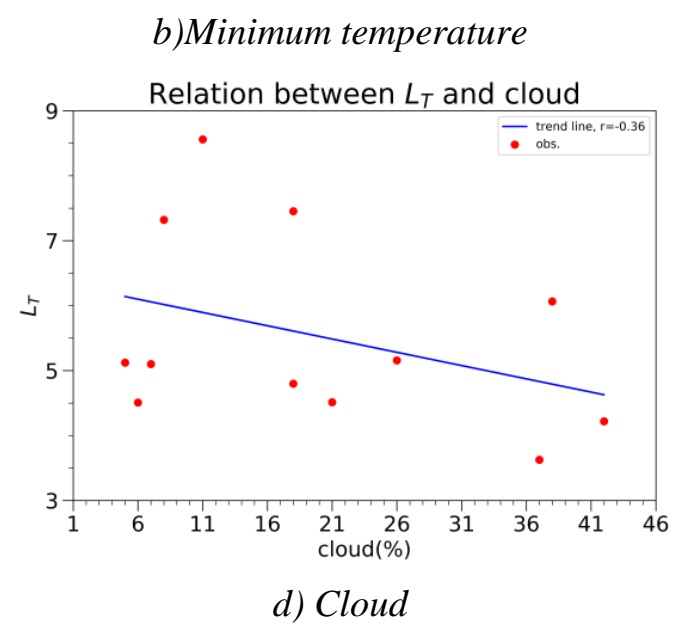

d) Cloud

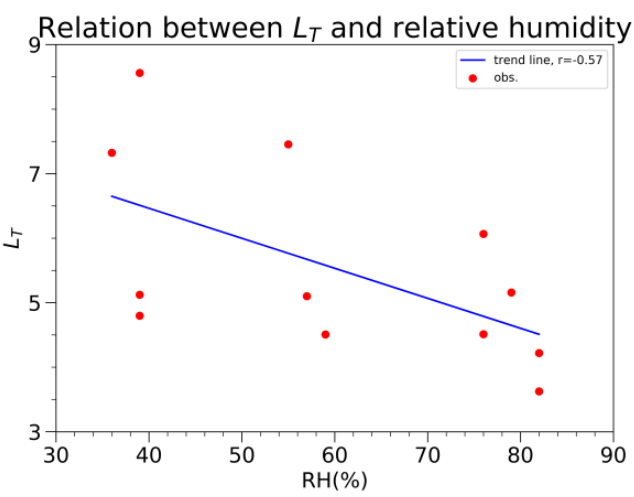

c)Relative humidity

Fig. 5: Relation of Linke turbidity with of parameters (Maximum temperature, Minimum Temperature, Relative humidity, Cloud) 
Figure 6(a) shows variation of Linke turbidity with water content. Correlation coefficient is 0.27 .Annual mean of water contend is $1.61 \pm$ $1.00 \mathrm{~cm}$. Figure 6(b) shows variation of Linke turbidity with ultraviolet. Correlation coefficient is 0.46 .Figure 6(c) shows variation of Linke turbidity with total ozone column (TOC).

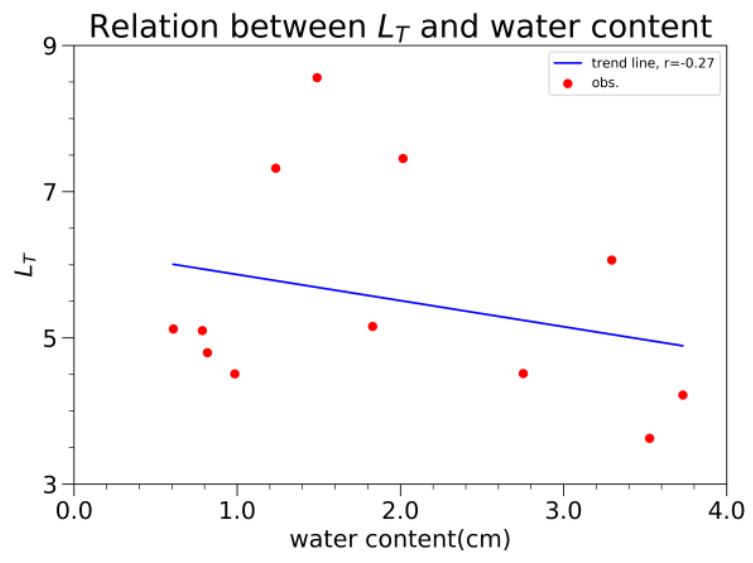

a)Water content

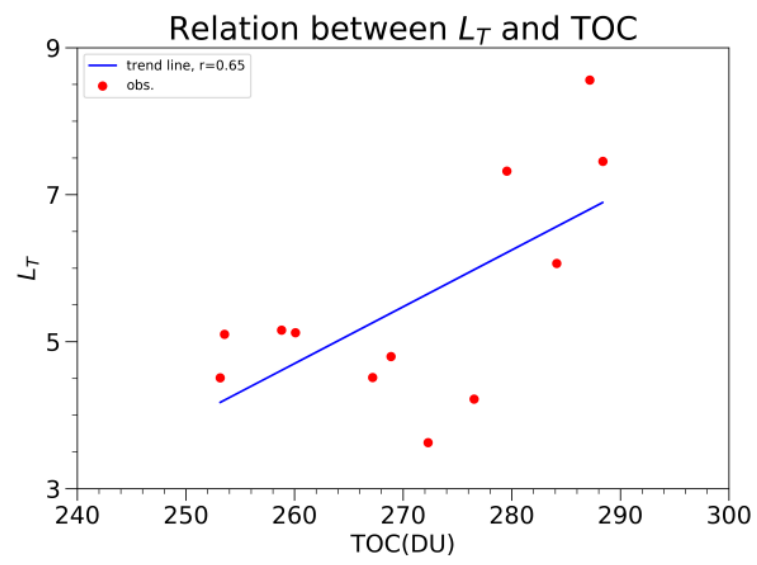

c)TOC
Correlation coefficient is 0.65 . Annual mean of TOC is $270.8 \pm 1.9$ DU. Figure 6(d) shows variation of Linke turbidity with $\mathrm{NO}_{2}$. Correlation coefficient is 0.77 . Linke turbidity is highly correlated with $\mathrm{NO}_{2}$. Figure 6(e) shows variation of Linke turbidity with wind. Correlation coefficient is 0.49 .

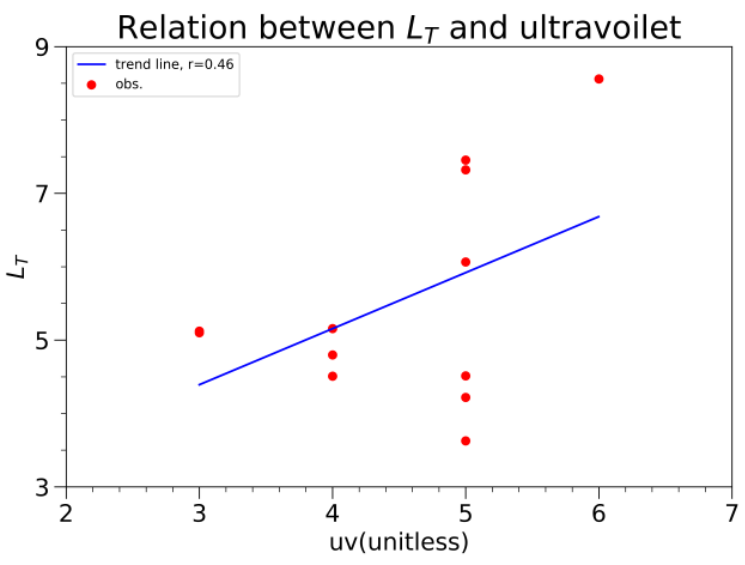

b)Ultraviolet

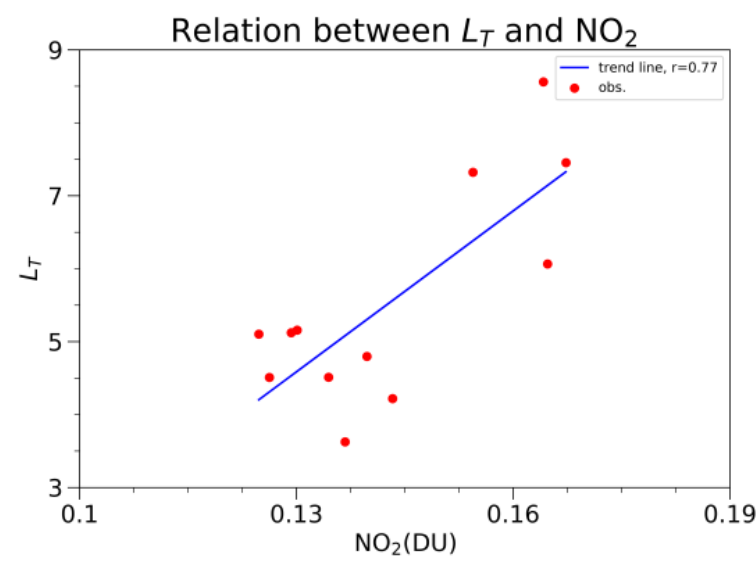

d) $\mathrm{NO}_{2}$

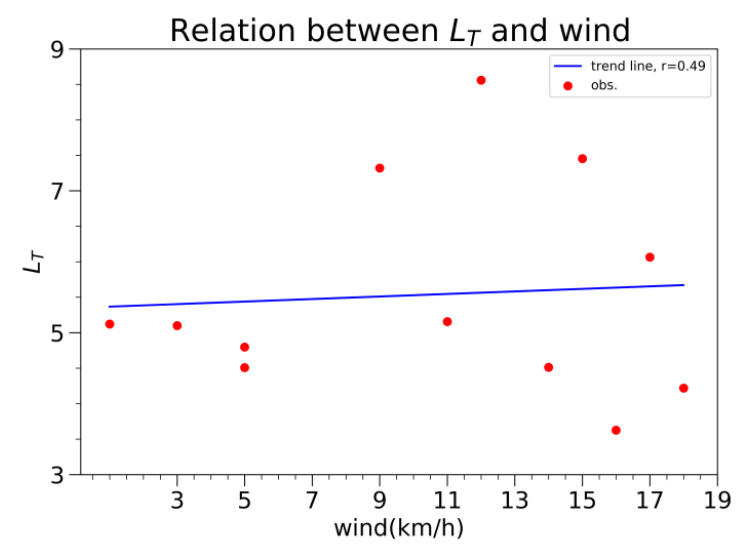

e)wind

Figure 6: Relation of Linke turbidity with of parameters (Water content, Ultraviolet, $\mathrm{TOC}$. $\mathrm{NO}_{2}$, wind) 


\section{CONCLUSIONS}

The annual mean value of parameter of Bode for study period 2013 is calculated. The annual mean of solar insolation, Angstrom exponential $(\alpha)$, Angstrom turbidity coefficient $(\beta)$, Linke turbidity factor $\left(\mathrm{T}_{\mathrm{L}}\right)$ and visibility are $4.70 \pm 1.10$ $\mathrm{kWh} / \mathrm{m}^{2} /$ day, $1.13 \pm 0.21,0.18 \pm 0.14,5.70 \pm 2.46$ and $2.98 \pm 2.13 \mathrm{~km}$ respectively. Linke turbidity is positively varies with TOC and $\mathrm{NO}_{2}$.

According to Wang [14] ,Linke turbidity values is 3.3 to 7.7 in Wuhan(latitude $30^{\circ} 32^{\prime} \mathrm{N}$, longitude $114^{0} 21^{\prime} \mathrm{E}$ and $30 \mathrm{~m}$ a.s.l.), Central China from 2010 to 2011.According to Laxmi Narain and S.N. Garg[17], on eight years(1993 - 2000)study, Linke turbidity for four cities of India are $T_{L}=7.5$ for Kolkata $\left(26.93^{0} \mathrm{~N}, 88.45^{\circ} \mathrm{E}, 431 \mathrm{~m}\right.$ a.s.1. $), \mathrm{T}_{\mathrm{L}}=4.6$ for Poona $\left(18.530 \mathrm{~N}, 73.85^{\circ} \mathrm{E}, 559 \mathrm{~m}\right.$ a.s.1.), $\mathrm{T}_{\mathrm{L}}=$ 6.4 for Jaipur $\left(26.93^{\circ} \mathrm{N}, 88.45^{0} \mathrm{E}, 431 \mathrm{~m}\right.$ a.s.l. $)$ and $\mathrm{T}_{\mathrm{L}}=6.8$ for New Delhi $\left(22.65^{0} \mathrm{~N}, 88.45^{0} \mathrm{E}, 216 \mathrm{~m}\right.$ a.s.l.). A comparison of observed values of turbidity parameter with other major cities of the world shows that Bode is as highly polluted as cities like Jakarta, Kansas, Beijing, Vienna, etc.

\section{ACKNOWLEDGMENT}

The authors would like to convey our gratitude to faculty of CDP, Patan Multiple Campus, IoST for this opportunity as well as NASA for the data. We sincerely appreciate NAST for the PhD fellowship. We also like to acknowledge Nepal Physical Society (NPS) and Association of Nepali Physicists in America (ANPA) for educational workshop of Python.

\section{REFERENCES}

[1] Shrestha, J. N.; Bajracharya, T. R.; Shakya, S. R.; and Giri, B. Renewable energy in Nepal-progress at a glance from 1998 to 2003. In Proceedings of the International Conference on Renewable Energy Technology for rural Development (RETRUD-03), 12-14 (2003).

[2] MoF. Economic Survey 2016/017. Ministry of Finance, Government of Nepal, 2016/017.

[3] DTM. Register vehicles till fiscal year BS 2074/075, BS 2075.

[4] Poudyal, K. N.; Bhattarai, B. K.; Sapkota, B. K.; and Kjeldstad, B. Solar radiation potential at four sites of Nepal. Journal of the Institute of Engineering, 8(3): 189-197 (2011).

[5] Sapkota, B. K. and Dhaubhadel, R. Atmospheric turbidity over Kathmandu Valley.Atmospheric Environment, 36(8): 1249-1257 (2002).
[6] Thapa, M. K.; Bhattarai, B. K.; Gurung, S.; Sapkota, B. K.; Poudyal, K. N.; and Karki, N. R. Effects of aerosols on the solar radiation in Midhill of Nepal: a case study in the Kathmandu Valley. International Journal of System Assurance Engineering and Management, 8(1): 54- 62 (2017).

[7] Shrestha, P. M.; Chapagain, N. P.; Karki, I. B.; and Poudyal, K. N. Variation on atmospheric transmittance solar radiation at Kathmandu Valley. Journal of Nepal Physical Society, 6(1): 105-112 (2020).

[8] CBS. National population and housing census 2011, 2011.

[9] Regmi, N. M. Temporal variation aerosols in Kathmandu,Nepal. Journal of PMC Physics Council, 1(1): 144-152 (2018).

[10] Lothian, G. F. Beer's law and its use in analysis. a review. Analyst, 88(1050): 678-685 (1963).

[11] Angstrim, A. Techniques of determinig the turbidity of the atmosphere. Tellus, 13(2): 214223 (1961).

[12] Dogniaux, R. Représentations analytiques des composantes du rayonnement lumineux solaire:conditions de ciel serein. Institut royal météorologique de Belgique, 1974.

[13] Iqbal, M. An introduction to solar radiation. New York: Academic Press, 1983.

[14] Wang, L.; Chen, Y.; Niu, Y.; Salazar, G. A., and Gong, W. Analysis of atmospheric turbidity in clear skies at Wuhan, Central China. Journal of Earth Science, 28(4): 729-738 (2017).

[15] Adam, M. N.; and Nobi, E. F. E. Correlation between air temperature and atmospheric turbidity at a subtropical location. World Environment, 7(1): 1-9 (2017).

[16] Koschmieder, H. Theorie der horizontalen sichtweite. Beitrage zur Physik der freien Atmosphare, 33-53 (1924).

[17] Narain, L. and Garg, S. N. Estimation of linke turbidity factors for different regions of India. International Journal of Environment and Waste Management, 12(1): 52-64 (2013). 